\title{
2006-1473: PREPARING STUDENTS TO COMPETE IN THE GLOBAL MARKETPLACE
}

\section{Natalia Kapli, Pennsylvania State University}

Natalia V. Kapli is a doctoral candidate in Instructional Systems at Penn State. She received her B.A. in Modern Languages and Education from Novosibirsk State Pedagogical University in Russia and her M.S. in Adult Learning, Performance \& Development from Drake University. Before starting graduate school she worked in both academic and corporate settings for four years. Address: 315 Keller Building, University Park, PA 16802. Telephone: 814-769-9014, email: nvk104@psu.edu

\section{John Wise, Pennsylvania State University}

John C. Wise is Director of Engineering Instructional Services at Penn State. In this capacity, he provides assistance to faculty members and teaching assistants in the areas of teaching, learning, instructional technology, and assessment. He received his B.A. in Liberal Arts from The University of the State of New York and his M.S. and Ph.D. in Instructional Systems at Penn State. Address: 201 Hammond Building, University Park, PA 16802. Telephone: 814-865-4016, FAX: 814-865-4021, email: jwise@psu.edu

\section{Thomas Litzinger, Pennsylvania State University}

Thomas A. Litzinger is Director of the Leonhard Center for the Enhancement of Engineering Education and a Professor of Mechanical Engineering at Penn State, where he has been on the faculty for 19 years. Prior to his appointment as Director of the Leonhard Center, he was ECSEL local principal investigator and the Coalition-PI for Student and Faculty Development. His work in engineering education involves curricular reform, teaching and learning innovations, faculty development, and assessment. He has received numerous teaching awards including the Alumni Teaching Fellow Award and the Eisenhower Award for Distinguished Teaching. He has also received an Outstanding Research Award and an NSF Young Investigator Award. Prior to joining Penn State, Dr. Litzinger had four years of industrial experience with General Electric, and completed his Ph. D. studies at Princeton. Address: 201 Hammond Building, University Park, PA 16802. Telephone: 814-865-4015, FAX: 814-865-4021, email: TALME@engr.psu.edu

\section{Wesley Donahue, Pennsylvania State University}

Wesley Donahue is an Associate Professor affiliated with both The Smeal College of Business Administration and the College of Education, and he is the Director of Management Development. Dr. Donahue brings over 25 years of manufacturing, sales and organization development experience to his position at Penn State. Formerly, he worked with the Fortune 500 company Brockway Inc., now Owens-Brockway, where he began as a project engineer and rose to manager of technology for the corporation's international division. Subsequently, he co-founded and served as Executive Vice President of Leffler Systems of New Jersey, a manufacturer of plastic containers and specialized machinery, after which he moved on to become regional Vice President of sales for Marketing Plastics in Kansas City, MO. In addition, he served as a professional associate of MGA Inc., a worldwide provider of technical management professional services to the packaging industry. He also owned a successful retail business for over 10 years. Dr. Donahue earned a B.S. in Engineering from Penn State, an M.B.A. from Clarion University, and a Ph.D. in Workforce Education from Penn State. He is also a registered Professional Engineer. Address: 506 Keller Building, University Park, PA 16802. Telephone: 814-865-6341,FAX: 814-865-5597, email: wed105@psu.edu 


\title{
Preparing Students to Compete in the Global Marketplace
}

\begin{abstract}
As globalization continues to relocate technical engineering jobs from the United States to overseas locations, it is critical that engineering programs in the U.S. consider the development of skills and abilities that will set their graduates apart and allow them to compete with their overseas counterparts. This paper describes a new course that is intended to provide this type of experience for undergraduates. The course makes use of e-learning technology and active learning techniques to develop graduates who will be comfortable communicating across cultures using technology to manage projects, team relationships, and collaborative design projects. The course was pilot-tested in the ' $04 /$ ' 05 academic year, with results from the formative assessment incorporated as appropriate.
\end{abstract}

\section{Background}

The increasing migration of technical engineering functions from firms located in the continental United States to overseas competitors has created an environment that calls into question how engineering undergraduates should be trained and educated. While some companies are battered and turn to overseas labor for relief ${ }^{1}$, engineering educators look to foster creativity and innovation to enhance the engineering student's ability to compete ${ }^{2}$. The Advisory Board for the Leonhard Center for the Enhancement of Engineering Education at Penn State recognizes this global challenge and advocates that engineers truly become "world class" ${ }^{3}$. The Board has made recommendations to the College of Engineering regarding specific enhancements that are necessary for our graduates to compete globally. As a result of those recommendations, Penn State is offering a new course - Professional Skills and Core Leadership Competencies in the Global Environment - that is specifically designed to respond to the aforementioned global engineering challenges. This paper will describe the design and execution of the class and the results of the course assessment to date.

\section{Description of the Course}

The course is problem-based and technology supported, and seeks to create a learning environment that replicates the geographically dispersed, team-oriented practices of engineers in the field. Among the tasks that the students must complete are on-line training modules with associated assessment, role playing exercises, and preparation of an individual portfolio that includes a short video clip in which students "sell" themselves to a prospective employer. The first iteration of the course was implemented and evaluated as an Engineering Leadership elective, and is a foundational course for students preparing for leadership positions. Its purpose is to ensure that all students develop an adequate understanding of contemporary professional skills and core leadership competencies that are needed to function effectively in today's global business environment. These skills include: 
- Collaboration / Multi-Disciplinary Team-Building Skills

- Leadership in Diversely Distributed Team Environments

- Interpersonal Communication Skills in the Workplace

- Conflict Resolution / Human Performance Management Skills

- Project Management Skills

- Problem-Solving / Creative Thinking / Ethical Decision Making

- Contemporary and Emerging Technology Usage

The instructor for this course was an associate professor affiliated with both the Smeal College of Business Administration and the College of Education. He was also the director of management development programs and services for the university. He was the sole instructor for the course, and primarily responsible for the development of the course content.

The pilot course implemented in the Fall of 2004 was to be a 50/50 mix of engineering and sociology students, but engineering students soon discovered that they could register through the sociology department. As a result, engineering students made up a majority of the twenty-four students enrolled in the course. The remainder were sociology and psychology students. There is some anecdotal evidence that the students enjoyed having peers from other programs in the course, but no formal assessment was made as to the effect of this arrangement on student learning.

\section{General Format}

The format of the course was blended. Half of the sessions were held in a classroom, and half were online. During the first two class meetings, the instructor introduced the course and course objectives, and discussed the first of the topics - interpersonal communication. During the second period, the instructor distributed a conflict questionnaire, and the group discussed their individual results. The rest of the face-to-face sessions were reserved for team presentations and demonstration of the final project.

The online sessions allowed students to work individually on Web-based training (WBT) modules. The modules were available through the university, and presented information on topics such as interpersonal communication, conflict resolution, new technologies and others ${ }^{4}$. The information in the modules was delivered in textual, visual and audio format, and also included an interactive simulation and a topical quiz. In addition to the WBT, students were expected to read paper-based course materials on the topics of communication in the workplace, understanding the global business environment, leading and managing complex projects, solving problems and making decisions, and contemporary technology usage. Each topic was modular, and can be offered independent of the others. The information in the paper-based supporting materials was basically a summary of the content of the WBT. These supporting materials were developed to serve as an additional resource and a supplement for the WBT modules, as well as to be a reference for the teams when they were preparing for their presentations.

Face-to-face classroom and online sessions were evenly distributed throughout the semester to allow time for the completion of both online and paper-based modules and for the preparation of team presentations. 


\section{Group Activities and Assignments}

A large portion of class activities was organized around small groups of students working in teams. Throughout the semester, students in teams of 4-5 people prepared 5 presentations on topics indicated in the syllabus. The main characteristic of the implementation of the team approach was that the groups consisted of different members for each presentation. This provided students with an opportunity to get to know their classmates better, and at the same time gain experience collaborating with people possessing different interpersonal communication styles. The topics and team course activities are listed in Table 1.

\begin{tabular}{|l|l|}
\hline Topic & Typical Team Course Activity \\
\hline $\begin{array}{l}\text { Communication in the Workplace: } \\
\text { Interpersonal Conflicts }\end{array}$ & $\begin{array}{l}\text { Ten minute role-play in front of the class } \\
\text { demonstrating a workplace conflict situation } \\
\text { between parties with different interpersonal } \\
\text { styles and how a leader should conduct a } \\
\text { performance coaching session. }\end{array}$ \\
\hline $\begin{array}{l}\text { Communication in the Workplace: People from } \\
\text { Different Cultures }\end{array}$ & $\begin{array}{l}\text { Ten minute role-play or skit of a negotiation } \\
\text { interaction between parties with different } \\
\text { cultural backgrounds, along with a three page } \\
\text { research paper describing cultural differences } \\
\text { and strategies for negotiation. }\end{array}$ \\
\hline $\begin{array}{l}\text { Global Business Environment: Conducting } \\
\text { Meetings at a Distance }\end{array}$ & $\begin{array}{l}\text { Ten minute technology assisted demonstration } \\
\text { meeting among multi-disciplinary and } \\
\text { geographically dispersed groups. }\end{array}$ \\
\hline $\begin{array}{l}\text { Leading Complex Projects: Project } \\
\text { Management }\end{array}$ & $\begin{array}{l}\text { Ten minute in-class presentation on how a } \\
\text { particular project should be managed from start } \\
\text { to finish. }\end{array}$ \\
\hline Solving Problems and Making Decisions & $\begin{array}{l}\text { Ten minute presentation using a tri-fold poster } \\
\text { to illustrate the use of their selected continuous } \\
\text { improvement tools. }\end{array}$ \\
\hline
\end{tabular}

Table 1. Course Topics and Team Activities

The presentation style varied, with two role-plays or skits, one technology-assisted talk, one PowerPoint ${ }^{\mathrm{TM}}$, and one poster-board session.

In addition to the team presentations, team members had to submit a 3-page research paper on the topic of their presentation as a team effort for the first two modules and as an individual effort for the third presentation. For the last presentation, the team was to submit their recommendations in the form of a formal written business proposal.

\section{Other Written Assignments}

Students were also required to maintain written individual reflection journals. Throughout the semester, students were expected to reflect on the content contained in the various web-based training modules and to make a record of their thoughts and possible applications of the content to their own lives. At the end of the semester, students consolidated their thoughts and 
application ideas into a personal career development action plan report that was submitted as a final individual project. In addition to the written report, students were asked to submit, in digital form, a presentation communicating why a workplace decision maker should consider them as a candidate for a leadership position. This presentation was to become a part of a personal web-site.

\section{Assessment Results and Discussion}

In Fall 2004, an extensive assessment of the first iteration of the course was conducted in order to make improvements to the syllabus before the course was offered in Spring 2005. The experimental group consisted of 24 students. The following data was collected:

- pre-course and post-course attitude survey,

- pre-course and post-course quizzes 1-4,

- pre-course reflective essays (20 participants),

- research paper based on case scenarios(groups 1-5),

- reflective journals and plans of action (individual),

- class observations (video and notes),

- focus groups (2 groups, 17 participants total),

- Leadership Competency Self-Assessment,

- Course Questionnaire,

- Course Syllabus/objectives,

- Course content (paper-based modules 1-5),

- Web-Based Training modules (designed and developed by Penn State University), and

- Course web-site usage

At the time of this writing, only pre- and post-course quizzes, pre-course essays, pre- and postcourse surveys, and partial focus groups from the first semester of implementation have been analyzed. The assessment of the course is by nature formative, and improvements are implemented as the data is interpreted.

\section{Pre-Course Essays}

During the first week of classes, the students in the course were asked to write a short (one or two-paragraph) essay, explaining their expectations for the course and how they expected the course to help them in their future career. Twenty students completed the assignment. Content analysis of the essays revealed the following themes, which were dominant throughout the majority of the essays, identifying students' perceived areas of weakness and their expectations for the course:

1. The course offers unique content. Many students indicated that this course content is not being offered in other courses in the College of Engineering.

2. The students expected this course to give them a competitive edge over other engineering graduates from both Penn State and other schools. 
3. Professional competencies were thought to be the major aspect where students feel they need improvement; students indicated that they need to develop such qualities as team work, client relations, problem-solving, and understanding the business context.

4. Most students mentioned that they know that they will probably work in a management position several years from graduation, and a management position requires good leadership skills. In this regard, it is important to remember that most students in this experimental group were already a part of the engineering leadership minor. Since most of them were also fourth and fifth year students, most already have either internship or co-op experience. They likely base their opinions about leadership on these real-life experiences.

5. Communication skills were believed to be very important for engineers by most respondents. Many see their careers in communicating with people and say that technical expertise is important, but to "climb a corporate ladder" they need to know how to communicate their ideas and their leadership.

6. Students were aware of the fact that the new business environment today involves diversity and a global market. Most students understand that diversity is either already existing or needed in the workplace; they also understand the global nature of business today and want to know how to work with other cultures.

7. Most students acknowledged the influence new technologies have on the workplace and on business operations.

8. Students hoped that this class will give them as close to a real life experience as possible.

These findings indicate that students were aware of the challenges and demands of the contemporary business environment and expected that the course would provide them with tools necessary for a future successful career.

\section{Pre/Post-Course Quizzes}

During the first week of classes students were also asked to complete a pre-test in the form of four multiple-choice quizzes. The content of the quizzes was based on the five course modules that were to be offered throughout the semester. The same quizzes were offered later in the semester (post-course) after the content of the corresponding modules had been presented. All quizzes were offered in an online format. Each student could complete the quiz at his/her own time and pace. As expected, the students performed much better on the post test of content knowledge, as shown in Table 2. This was the result of learning from the course modules, as well as possible additional resources. Only the scores from those students who have completed all four pre- and post-quizzes are included in the analysis $(\mathrm{n}=21)$. 


\begin{tabular}{|l|l|l|l|l|}
\hline & \multicolumn{2}{|l|}{ Pre-course Assessment } & \multicolumn{2}{l|}{ Post-course Assessment } \\
\cline { 2 - 5 } & Mean & SD & Mean & SD \\
\hline Module \#1: & 64.57 & 8.97 & 96.38 & 7.25 \\
\hline Module \#2: & 63.62 & 9.87 & 97.33 & 7.41 \\
\hline Module \#3: & 59.62 & 9.29 & 96.76 & 5.74 \\
\hline Module \#4: & 65.52 & 12.74 & 97.14 & 6.21 \\
\hline
\end{tabular}

Table 2. Mean Scores for Content Pre- and Post-Course Assessment

The results from paired t-tests for all four quizzes, where the post-test was compared to a corresponding pre-test, showed that the gains are statistically significant:

Module $1(\mathrm{t}=11.06, \mathrm{df}=20, \mathrm{p}<0.001)$

Module $2(\mathrm{t}=18.30, \mathrm{df}=20, \mathrm{p}<0.001)$

Module $3(\mathrm{t}=16.67, \mathrm{df}=20, \mathrm{p}<0.001)$

Module $4(\mathrm{t}=9.42, \mathrm{df}=20, \mathrm{p}<0.001)$

In addition, inter-item correlation (reliability) tests were conducted for all four post-tests with the following results: Quiz $1 \alpha=.84$; Quiz $2 \alpha=.92$; Quiz $3 \alpha=.72$; and Quiz $4 \alpha=.79$.

\section{Pre/Post-Course Surveys}

In addition to quizzes and pre-course essays, pre- and post-course surveys that were developed to measure students' attitudes toward the concepts covered in the course were conducted. The results presented in Table 3 indicate that even before taking the course, the students had a positive attitude as far as the importance of leadership, communication, and business management concepts for their future career in a contemporary business environment. This result can be explained by the fact that this group of students self-selected for the course, as it is not a required course, and the motivation for these students was already high. The post-test scores indicated improvement in most areas, except for leading and managing complex projects. The reason for this finding may be that the students had learned that leading and managing projects included a number of different complex steps and required competency in certain areas that made it more difficult than they had initially thought.

Paired t-test for students who completed both pre- and post-course survey $(\mathrm{N}=8)$ showed a statistically significant attitude change towards engineering and business concepts by the end of the course $(t=7.18, d f=7, p<0.001)$. The low response rate $(33 \%)$ mitigates this result. 


\begin{tabular}{|l|l|l|l|l|}
\hline & \multicolumn{3}{|l|}{ Pre-Course N= 24 } & \multicolumn{2}{l|}{ Post-Course N = 8 } \\
\hline & Mean & SD & Mean & SD \\
\hline $\begin{array}{l}\text { 1) I can use online technologies for } \\
\text { team projects. }\end{array}$ & 4.12 & 0.95 & 4.75 & 0.46 \\
\hline $\begin{array}{l}\text { 2) I think diversity of opinions is } \\
\text { critical to the successful completion } \\
\text { of complex team projects. }\end{array}$ & 4.29 & 0.69 & 4.62 & 0.52 \\
\hline $\begin{array}{l}\text { 3) I know how to deal effectively } \\
\text { with conflicts in teams. }\end{array}$ & 4.00 & 0.66 & 4.62 & 0.52 \\
\hline $\begin{array}{l}\text { 4) Working in a global business } \\
\text { environment is very similar to } \\
\text { working for a local company. }\end{array}$ & 2.37 & 0.97 & 2.00 & 1.31 \\
\hline $\begin{array}{l}\text { 5) I'm confident that I can lead and } \\
\text { manage a complex project. }\end{array}$ & 4.00 & 0.59 & 3.62 & 1.06 \\
\hline $\begin{array}{l}\text { 6) Communicating with people from } \\
\text { other cultures is pretty much the } \\
\text { same as communicating with people } \\
\text { in my own culture. }\end{array}$ & 2.04 & 1.00 & 1.37 & 0.52 \\
\hline $\begin{array}{l}\text { 7) Leaders need to be good at } \\
\text { 'coaching'. }\end{array}$ & 3.87 & 0.90 & 4.62 & 0.52 \\
\hline $\begin{array}{l}\text { 8) 'People skills' are not as important } \\
\text { as technical expertise. }\end{array}$ & 1.50 & 0.72 & 1.37 & 0.52 \\
\hline $\begin{array}{l}\text { 9) Most engineering students will } \\
\text { work for ten years before taking a } \\
\text { leadership position. }\end{array}$ & 2.71 & 1.04 & 3.00 & 1.19 \\
\hline $\begin{array}{l}\text { 10) The best teams are made up of } \\
\text { people with similar backgrounds. }\end{array}$ & 1.79 & 0.66 & 1.25 & 0.53 \\
\hline $\begin{array}{l}\text { 11) Engineers educated in other } \\
\text { nations are generally less qualified } \\
\text { than engineers educated in the } \\
\text { United States. }\end{array}$ & 1.87 & 0.80 & 2.00 & 0.52 \\
\hline $\begin{array}{l}\text { 12) I am able to resolve conflicts in } \\
\text { my work environment. }\end{array}$ & 4.04 & 0.55 & 4.50 & 0.52 \\
\hline $\begin{array}{l}\text { 13) I can clearly explain why cultural } \\
\text { awareness is important in the } \\
\text { workplace. }\end{array}$ & 4.12 & 0.68 & 4.62 & 3.75 \\
\hline $\begin{array}{l}\text { 14) I can apply project management } \\
\text { tools to lead an engineering project. }\end{array}$ & 3.58 & 0.83 & 3.75 & \\
\hline $\begin{array}{l}\text { 15) I think it's important to have a } \\
\text { professional portfolio. }\end{array}$ & 4.25 & 0.67 & 4.62 & \\
\hline
\end{tabular}

Table 3. Mean Scores for Pre- and Post-Course Attitude Surveys. "1" = "Strongly Disagree", " 2 " = "Disagree", "3" = "Neutral", "4" = "Agree", "5" = "Strongly Agree". Items 4, 6, 8, 10, and 11 are reverse-scored. 


\section{Focus Groups}

The preliminary results from the focus groups show that there are several areas in the course structure that need to be addressed in the next iteration of the course. While students who participated in the focus groups gave a generally very positive evaluation of the course, citing its unique content, hands-on structure, and overall atmosphere as the most valuable aspects of the experience, at the same time three major areas of concern were identified from the focus group discussion:

1. The WBT (web-based training) needs to be restructured. The first iteration of the course included 24 WBT modules with an average time of around 1 hour needed for the completion of each module. At the same time, there were no assignments directly associated with these modules, which resulted in students assigning a very low priority to completing the WBT, especially towards the end of semester.

2. Feedback following class presentations has to be more consistent. During the first iteration of the course, feedback was used periodically and mostly provided by the instructor. There were no strategies in place to promote consistent instructor and peer feedback, and almost no improvement suggestions were given to groups when they produced mediocre presentations.

3. The three-page group papers appeared to be difficult to implement, as students working together in groups of 4 to 5 were having difficulty developing strategies for producing coherent short papers. One of the possible reasons for this problem is that students had to switch groups for each short paper and could not quickly adjust to their team members work schedules.

\section{Changes Made}

Based on the results of these and other assessments, several changes were made to the course before it was offered in the spring of 2005. First of all, the number of WBT modules was reduced from 24 to 12. Each of these modules is now due by a particular class session during which each student has to be ready to present a 3-minute report on the content of the WBT module. During the class session, a student is randomly selected to report on the module, and three other students are also randomly selected to keep time and to provide feedback on content coverage and presentation skills. This new structure provides more opportunities for peer feedback and stimulates completion of the WBT modules.

Three-page group papers were eliminated altogether, with more emphasis now being on individual reflective papers which follow each group presentation. The concentration on individual papers will allow students to reflect more deeply on the topics and will help them demonstrate their individual understanding of the material.

Another change for the second iteration of the course is incorporating more technologies into the course and providing students with more opportunities to explore and practice different technology-based communication tools used in the contemporary business world. These 
technologies include audio and video conferencing, voice and video over the Internet, instant messaging and others.

\section{Conclusion}

Overall, the evaluation of the first iteration of the course produced very positive results. Most students admitted that the content of the course was very useful to their future career. The main reason cited by students was that business communication and project management content is not offered in any other courses within the engineering curriculum. This observation is not surprising; most of these students have not been exposed to the senior capstone experience, which is where project management is usually presented in the Penn State curriculum. This lack of project management exposure is supported by data provided by alumni, and is the primary impetus for the creation of this course.

The second reason why students enjoyed the course was because most of the activities were offered in a hands-on, interactive manner. Direct lecturing occupied very little time during class sessions, which is considerably different from most engineering courses that students take. At the same time, the level of achievement by most students in the course was very high, as indicated by the results of the post-course quizzes and other assignments. During the focus groups, students admitted that they felt they learned a lot from the course, even though some of the materials, such as WBT, could have been more useful.

Based on the evaluation results several major conclusions can be made about the first iteration of the course:

1. The iteration was generally very successful, with the majority of students enjoying the course. This success can be attributed to both the content of the course and the hands-on studentcentered structure of the course.

2. The course content was perceived by students as highly relevant to their future career. This finding is very important because most of the students who took the course are planning to graduate within 2-3 semesters, and some of them already have jobs.

3. Achievement on quizzes, presentations, attitude surveys and other assignments was very high, which indicates that a considerable amount of learning took place within the course.

4. There were several areas where improvement will need to be made, including restructuring the WBT modules, providing more instructor and peer feedback opportunities, and reconsidering written assignments. These changes will be tested in the Spring 2005 iteration.

Beginning in the Fall 2005 semester, the course was to be scaled up to eventually become a required course within the engineering curriculum. In order for this to happen, the course will need to be accepted as a "General Education" course. It is expected that enrollment in the course will be increased from 24 to at least 100 students per semester. This change in the audience will present new challenges for redesigning and adjusting the course to accommodate the larger number of students while at the same time maintaining the high quality of content and interaction 
in the course. One of the possible strategies that may support the expanding of the course is the use of technology-based communication tools to facilitate interaction among clusters of students otherwise isolated by time and location.

\section{Acknowledgement}

This study received support from The Leonhard Center for the Enhancement of Engineering Education $^{3}$.

\section{Bibliography}

1. Meredith, R. (2003). "Giant Sucking Sound", Forbes,September 29, 58-60.

2. McGraw, D. (2004). "Putting it into perspective", Prism, January, 24-29.

3. The Leonhard Center for the Enhancement of Engineering Education, "Homepage", < http://www.engr.psu.edu/LeonhardCenter/eec/lc/> (21 March, 2005).

4. Web-Based Training, "Homepage", $<$ https://wbt.psu.edu/>(21 March, 2005). 